\title{
Freight modal split models: data base, calibration problem and urban application
}

\author{
A. Cappelli \& S. Nocera \\ Università IUAV di Venezia, Italy
}

\begin{abstract}
In the last 15 years, freight market developments concerning organization, rules and data communication have determined a shift from planning to flexibility: this implies not only higher frequency and variety in the shipments, but also higher average speed, reliability and actual security of the travels.

It is also important to be able to forecast the modal choice of the customers within an acceptable approximation margin in these new conditions. The past attempts seem to prove that the nested logit models are currently the most studied and used tools for the forecast of the transport demand, and particularly for the modal split $[10,11]$.

The most difficult challenge is however the correct calibration of the freight modal split models. The experts in the field are nearly unanimous in affirming that the transport decision makers are not only sensitive to the parameters of the "classic" traffic models (above all, time and cost).

For these reasons, the best way to represent the effects on the demand is constructing a model based on a survey on both stated preferences (SP) and revealed preferences (RP) [9].

This paper shows the problems in describing the modal split in the freight models, concerning:

- $\quad$ an information system (Data Support System - DSS) able to describe the modal behaviours of the freight operators, as concern both the existing transport and new modes [5];

- the specification of meaningful variables also on the base of specific surveys and their complex interpretation in the reference scenarios, and the obvious problems of calibration of the results [7];

- the problem of calibration of the model at the national and urban level, on the base of the available DSS.

Keywords: freight transport, modal split, RP and SP surveys.
\end{abstract}




\section{The use of RP and SP in freight surveys}

The most employed techniques for estimating freight choice models are revealed preference (RP) and stated preference (SP). The former are based on observations of actual choices and allows one to characterise current travel behaviour, while the latter provide information about user preferences for new alternatives or for alternatives that differ radically from the existing ones. The combined use of both kinds of data surveys allow to exploit their respective advantages and to overcome their specific limitations $[3,4,8]$.

SP scenarios are characterised from the evaluation of new, sometimes nonexisting alternatives in the considered area: their most intriguing advantage is the concrete possibility to evaluate customers' reactions in hypothetical - and sometimes quite far from reality - situations. The most concrete risk is however a weak correspondence between answers regarding a fictitious scenario and the actual behaviour (this is normally known as "hypothetical bias").

The traditional RP techniques do not have such problems, as they register ex-post choices, allowing one hence to analyse the preferences and the behaviours of the customers in real situations. However, they show some big problems:

- A great number of variables is normally necessary to understand the behaviour of freight decision makers;

- The statistic estimation of the different variables is often unreliable;

- The organization, the management and the elaboration of the interviews and the choice of the sample to investigate have to be statistically correct.

\section{The correct construction of freight modal split models}

Freight mobility is a definitely more complex and articulated issue than passenger transport: the use of modal split models developed for passenger mobility is therefore normally ineffective.

The most significant difference between passenger and freight transport is to be related to the concept of "utility": passenger modal split models evaluate time and cost as the parameters influencing the choice between the different modes. Other factors are normally included in the disturbance terms [2].

Freight transport is normally influenced by a more complex series of prominent attributes, which are derived from time and cost only in a first approximation. These attributes have been already formally identified $[1,8,10]$, and may be listed as in table 1 .

A second big difference concerns the necessity of a peculiar approach that may hold into account the differences between the behaviour of the travellers and the freight transport decision makers.

The most interesting problem in the definition of the quality of the freight transport is not however the choice of the compelling factors, instead the way to sample and estimate the data deriving from the surveys. 
On the basis of the researches realized in the last 10 years in the Italian Regions of Emilia Romagna, Veneto, Puglia and Basilicata [7-9], this paper proposes some guidelines for the construction of a freight modal split model, which may represent the real choice behaviours of the freight operators, above all in the urban case.

Table 1: Factors of cost in passenger and freight transport (Source: [11], elaborated).

\begin{tabular}{|c|c|}
\hline Passenger & Freight \\
\hline \multirow{7}{*}{$\begin{array}{l}\text { Time (including } \\
\text { reliability) }\end{array}$} & Reliability of the transport time \\
\hline & Average speed \\
\hline & Regularity \\
\hline & Transport without breaking off \\
\hline & Availability of an immediate replacement \\
\hline & Distance \\
\hline & Empty legs \\
\hline \multirow{6}{*}{$\begin{array}{l}\text { Cost (including personal } \\
\text { evaluation of safety) }\end{array}$} & Packing \\
\hline & Transhipment \\
\hline & Delivery payment \\
\hline & Safeness \\
\hline & Dimension of the shipment \\
\hline & Advertising \\
\hline
\end{tabular}

\subsection{A correct evaluation of the generalized cost of the freight transport}

As said, passenger modal split models evaluate time and cost as the parameters influencing the choice between the different modes. The significant variables which have to be included in the freight modal split models are slightly different: in the utility function, price/cost and time have to be joined by a set of ulterior parameters, representative of both the quality of the transport and the confidence of the decision makers who base their choice on the reliability of the operators.

In a sense, these parameters can still be included in a "generalised cost" if also safety, punctuality and risk of delay are within its borders [8]. 
The correct estimation of these variables requires direct investigations, which are quite expensive and complex, and whose reliability must carefully be measured: direct surveys by expert interviewers have to be normally preferred to telephone interviews, which generally give disappointing results (Caprini et al. [9]).

\subsection{The quality of the data base for the transport demand}

The calibration of freight modal split models require availability of data coherent with the selected choice parameters (origin-destination matrices, performances of the transport network, reliability, regularity and tracing of the shipments).

Demand matrices are usually divided for transport mode, present often aggregate temporal references (per year or standard day) and are expressed in terms of tons of freight or cargo unit (truck, container, trains etc.) [6]. These data can't contribute to evaluate the quality of transport required by the customers if these are not consistent with other variables of transport reliability.

The problems in calibrating the models in such situation are connected with the different grade of description of the phenomenon to reproduce. The use of the modal constants at the end of the calibration, or the techniques of pivoting, may concur to balance quantitatively the observed and simulate data, hardening the ability of the model to simulate future scenarios characterized from substantial differences with the present time.

\subsection{Characteristics of the transport demand-supply data system for the correct simulation of the freight demand in the urban case}

The sample to survey requires a certain composition, stratification and numerousness, which must be verified on the system to be investigated, both for the reconstruction of the demand matrices and for the evaluation of future modal behaviours. This issue is statistically obvious, but practically complex: in the construction of a freight modal choice model, the referring universe must be clearly specified and investigated.

The difference with the case of the passenger transport is once again obvious and causes some uncertainty. The most complex models for the passenger demand divide the referring universe for income subsets, for the scope and the nature of the travel (short, medium, long distance): in any case, the object of the transport is always the person, sometimes distinguished by age subsets.

Freight transport simulation (concerning both modal behaviour and operator choice) has to take the following issues in the due consideration:

a. The transport object is defined by an aggregate term lacking in real significance: diamonds, iron, perishable food and clothing industry products are for instance all included in the term "freight". The articulation of the products is often reduced to some standard categories and also in this case the difficulties met are very relevant, as the sample turns out to be a large class.

b. The global referring statistical universe is also an issue. For example, Italian national statistical institute (ISTAT) elaborates every year the national 
matrix of the freight on the road (normally on interregional scale) by inquiring road national traffic (only Italian firms are investigated). This data does not offer coherent information about the global referring universe, since all not-national flows obviously do not belong to the survey - this is an important underestimation, due above all to the liberalization of the road cabotage within the European Union. This issue is even more complex if transport corridors are taken into account: in these cases, the construction of the transport demand matrices, even if carried out with the utmost care, refers to the so called "current demand", that is the one inquired with direct interviews (normally to the operators of the multimodal transport system) in the period of surveying. This gives information only about the transit flows on some screen lines, and in no case on the global universe.

c. This procedure assumes that the local flows are statistically representative for the whole universe crossing the screen lines: this assumption cannot be reliably checked and in no case it can be supposed a-priori. Misjudging a local sample for global is a obvious statistical error: for both the demand forecast and the study of the difference in the modal split deriving from a change in the supply, a significant sample of the in-transit flows disaggregated for time and kind of freight - should be instead investigated.

This issue is not unsolvable but has to be based on complete surveys. First of all, it is in fact necessary to inquiry a pilot sample for each screen line, through which both the main origins and destinations of the flows and the main transport operators have to be determined. Consequently, for each main line and for every freight category to investigate, a statistical sample of these operators should be investigated with a RP survey to understand the amounts of travelling freight and the offered quality of transport supply.

The same sample must be then investigated with a SP survey to understand the differences in the modal behaviours dependent from changing in the supply.

This allows to investigate the actual freight modal behaviours, to choose the strategic variables and then to forecast customer behaviour in the future different scenarios.

In the urban case, these problems may be quite easily overcome, as:

a. The amount of the freight categories is also to be considered much smaller in the urban case: the freight moving from/to the cities are only the ones necessary for the survival of the city itself (for instance, perishable and imperishable food, clothes, home and firm items, and so on);

b. A degree of freedom of the desire line is lost, belonging the origin (or the destination) of the freight to the borders of the city. In other terms, $n^{2}$ desire lines are reduced to $n$ desire lines.

c. The universe of the demand operators is imaginably more limited and steadier: habitual suppliers are generally known or can more easily be identified. This makes the SP surveying simpler and more reliable.

These three considerations lead to a strong reduction in the dimension of the data to inquiry and allow the construction of correct freight modal split models in the urban case. 


\section{Conclusions}

Freight modal split modelling is a complicate issue. Coherent results may be reached following two different approaches:

- Forgoing the construction and the calibration of aggregate demand matrices and modal split models, leaning instead on the disaggregated analysis of some specific productive supply chains and constructing evaluation analyses on these. This allows only a refined understanding of some single fields, but it is not enough for general transport plans or feasibility studies.

- Constructing consistent modal split models with joint RP-SP surveying, in which the forecast of the different future modal behaviours should be verifiable through the calibration of the observed real scenario (the demand matrix should be assigned to the transport network reproducing the counted flows on the investigated screen lines).

The second procedure is quite complex and gives demand matrices disaggregated for mode, freight category, and quality of supply. These matrices allow however the construction of modal split models which could effectively be calibrated on the transport network, given the availability of a coherent description of the current transport quality parameters by which such models have been constructed.

The laboriousness and the duration of this process, its high surveying costs and the objective difficulty to identify a significant sample of operators for each desire line and category can be slightly reduced in the urban case: this paper suggested steps towards a different implementation of urban freight modal split models should offer better results concerning both modal behaviour and operator choice.

\section{References}

[1] Bayliss B., 1988. The Measurement of Supply and Demand in Freight Transport, Avebury, UK

[2] Ben-Akiva, M., and Lerman, S.R. (1985): Discrete Choice Analysis: Theory and Application to Travel Demand. The MIT Press, Cambridge, MA, USA

[3] Ben-Akiva, M. and Morikawa, T., 1990. Estimation of travel demand models from multiple data sources. In: Proceedings 11th International Symposium on Transportation and Traffic Theory. Yokohama, Japan.

[4] Bradley, M.A., Daly, A.J., 1997. Estimation of logit choice models using mixed stated-preference and revealed-preference information. In: Stopher, P.R., Lee-Gosselin, M.E. (Eds.), Understanding Travel Behaviour in an Era of Change. Pergamon, Oxford.

[5] Cappelli A., Libardo A., and Nocera S. (editors) (2005): Limiti e prospettive di sviluppo del trasporto ferroviario merci. Aracne, Rome, Italy. ISBN 88-548-0275-1 
[6] Cappelli A., Libardo A., and Nocera S. (2005): The Relations between Regional Economic Development and Evolution of Transport Demand in Italy. Proceedings of $3^{\text {rd }}$ International SIIV Congress, September 2005, Bari, Italy

[7] Cappelli A. et al. (2004): Territorio, Imprese, Logistica: stato dell'arte e linee di intervento regionale. Quaderni del Servizio Pianificazione dei Trasporti e Logistica, Servizio Stampa Regione Emilia Romagna

[8] Cappelli A., Petruccelli U. and Carbone A.M. (2004): Metodologie di indagine per la calibrazione della funzione di utilità percepita del trasporto merci. T\&T - Trasporti \& Territorio, 3, 107-115

[9] Caprini A., Gastaldi M., Nocera S., and Rossi, R. (2004): Analisi dei fattori che condizionano le scelte attuali di trasporto merci: risultati di un'indagine in quattro distretti produttivi del Veneto. Proceedings of the National SIDT Congress, 23rd -24th September 2004, Rome, Italy (in print)

[10] Cullinane K., and Toy N. (2000): Identifying influential attributes in freight route/mode choice decisions: a content analysis. Transportation Research Part E: Logistics and Transportation Review, 36-1: 41-53

[11] Montella B., Di Gangi M., and Russo F. (1995): I modelli di ripartizione modale per il trasporto merci. In: Cascetta E., and Salerno G.: Sviluppi della ricerca sui sistemi di trasporto. Collana Società italiana dei docenti di trasporti, Franco Angeli, Milan, Italy 